\title{
Forming a Model of Cost Management in the Regional Scientific-Educational Cluster
}

Timiryasova A.V. ${ }^{a}$

\author{
Safiullin L.N. ${ }^{b}$ \\ Kramin T.V.c \\ Grigoriev R.A. ${ }^{d}$
}

\author{
acd Institute of Economics, Management and Law, Kazan, Russian Federation, 420111 \\ ${ }^{b}$ Kazan Federal University, Institute of Management, Economics and Finance, Kazan, 420008, Russia
}

\section{Doi:10.5901/mjss.2015.v6n1s3p96}

\begin{abstract}
The work presents a model of the organizations' interaction in the framework of the regional scientific-educational cluster, based on the cost approach. When using the hierarchical structure of the cost management system, a new classification of cluster interactions and the clusters themselves was formed, which takes into account not only economic, but also institutional factors. In particular, the model of cluster interactions takes into account the key areas of the organization competence, playing a significant role in enhancing the competitiveness of educational institutions in the post-industrial economy.
\end{abstract}

Keywords: institutional environment, scientific-educational cluster, cost approach, cost management, educational institution

The cluster approach is becoming more and more widespread, both in theory and practice of modern management. However, the modeling of cluster schemes is not paid sufficient attention to: the researchers in the field of clustering focus mainly on sectoral and regional aspects. At the same time, the post-industrial economic development requires a new view on the nature of clusters. In the present work, a cluster is considered on the basis of the concept of business value management and institutional approach.

The work models organizations' interaction in the framework of the regional scientific-educational cluster ${ }^{1}$, based on the cost approach.

Starting with the famous works by M. Porter (M.E. Porter, 1986), many publications were devoted to the modeling of clusters. Many of them are based on the "competitiveness diamond" by M. Porter. Thus, the work by I.R. Ferova (Ферова, 2005) describes the educational model of local industrial clusters based on "competitiveness diamond" by M. Porter, including the following diamond-forming components:

1. The firm's strategy and forms of competition (intense competition between rival firms located in the same area).

2. Features of production resources (local resources: labour, capital, natural resources; natural, administrative, informational and technological infrastructure, specialized factors of production).

3. Local features (the features of the habitat that stimulate appropriate forms of investment and constant renovation).

4. Features of demand (local consumers with a high level of product requirements, specialized factors of demand, customer needs, the occurrence of which can be expected everywhere).

5. Development of auxiliary and servicing enterprises (the presence of potential suppliers and competing production in the same area).

In other works modelling is used as a means of forming the classification and grounding the clusters typology (Ферова, 2005). Thus, the modelling results by I. Gordon, P. McCann can be presented in the following tabular form (Gordon \& McCann, 2000) (see Table 1).

It is an undeniable fact that any model is an ideal construction, intended to explain the behavior of real objects. In this sense, in reality there is no "pure" cluster, which could only be described using one of the above models.

1 Features of educational factors development (Amaral, Ferreira, \& Teodoro, 2011; Chapman, Smith, Wood, Barnes, \& Romeo, 2011; Korchagin, Safin, Vildanov, \& Abitov, 2014; Mayer, 2007; Peters, 2006; Вахрушева, 2009) 
When modeling clusters, one should take into account the modern trends in the development of the post-industrial economy. Currently, the social sphere (Gavrilov \& Yaw, 2013) has a large impact on economic processes, including on appearing and forming of clusters.

Table 1. Classification models by I. Gordon and P. McCann

\begin{tabular}{|l|l|l|}
\hline $\begin{array}{l}\text { Pure model of economy } \\
\text { by agglomeration }\end{array}$ & Industrial complex model & Social network model \\
\hline $\begin{array}{l}\text { Special attention is paid to } \\
\text { the external effects of } \\
\text { geographical } \\
\text { concentration }\end{array}$ & $\begin{array}{l}\text { Clusters are space participants of intersectoral } \\
\text { balance models in the regional economy, } \\
\text { geographical agglomeration which appeared } \\
\text { through inter-company trade links and minimizing } \\
\text { transactional costs }\end{array}$ & $\begin{array}{l}\text { Clusters are solid local networks, } \\
\text { interaction in which is carried out on the } \\
\text { basis of interpersonal, trustful relations, } \\
\text { within the formed institutional } \\
\text { environment }\end{array}$ \\
\hline
\end{tabular}

M. Porter marks: " cluster theory also provides a way to connect theories of networks, social capital, and civic engagements more tightly to business competition and economic prosperity—and to extend them. Moreover, ... Clusters offer a new way of exploring the mechanisms by which networks, social capital, and civic engagement affect competition and market outcomes... Cluster theory ... Cluster theory may also reveal how network relationships form and how social capital is acquired" (Michael E Porter, 2008, p. 243). Thus, M. Porter takes into account the importance of the social sphere (in particular, social networks) in the formation and functioning of clusters. At the same time, the mechanism of the influence of social and institutional aspects in cluster models is not discussed in detail. The empirical research on the social and information networks within the cluster also does not consider the intra-cluster institutional environment.

The trend of the recent years is to spread clusters in the world economy (Den Hertog \& Remoe, 2001). Moreover, clusters are now increasingly considered not only as a theoretical model, but also as a tool of economic policy. This is due to the fact that the cluster concept is naturally combined with the development of the information economy, knowledge economy. According to D. North, the reason of the US global leadership in the new economy is the existence of several large, dynamically developing clusters of innovative entrepreneurship activity in this country (Норт, 1997).

Completing a brief overview of works in the field of cluster schemes modeling, we should make the following conclusion. In the methodological sense, the modeling of clusters in these works is mostly of a summarizing nature (for example, based on the "diamond of competitiveness" by M. Porter). The importance of social aspects in the cluster approach is marked; however, a complex institutional theory is not applied in cluster analysis. In addition, the cluster is not considered as a tool of company value management. The studies of this work are intended to eliminate these gaps.

The key feature of the cluster is to increase the competitiveness of the companies included in it $^{2}$. Classically it is believed that one of the sources of this increase is the increase in production factors efficiency. In the post-industrial economy, however, the emphasis is shifted from production and distribution factors to the intangible, institutional ones. Moreover, particular importance in the cluster is attributed to the exchange and sharing of key areas of competencies of its participants.

Currently, the most important branch of management is the management of business value (Copeland, Koller, \& Murrin, 1994). The development of capital markets both abroad and in Russia led to the need for companies to maximize their value (Т.В. Крамин \& Ю.С. Церцеил, 2008). The company value management has become a critical mandatory function of its top management and all employees under their jurisdiction. In this paper, it is proved that the cluster approach is an effective tool of the company cost management.

Anticipating the rationale for the efficiency cost approach in the management of scientific-educational cluster, we will consider a model of company value management system, developed by T.V. Kramin (T. Крамин, 2006).

The system considers the subjects and objects as well as the principles of their interaction (Table 2). When using the institutional approach, the group of subjects of the cost management system significantly expands, exceeding the limits of the company management and its owners. In addition, the most important object cost management system is its institutional environment, including the complex system of intra-company institutions.

${ }^{2}$ Aspects of regional competitiveness increase (Lefebvre, Pallez, \& Fixari, 2009; Safiullin, Fatkhiev, \& Grigorian, 2014; Safiullina, Ivanov, \& Beloborodova, 2014; Safiullina, Ivanov, \& Ramazanov, 2014; Safiullina, Odintsova, Zhilina, \& Shamsutdinova, 2014; Safiullina, Volkova, Petukhova, \& Guseva, 2014). 
Table 2. Elements of cost management system

\begin{tabular}{|l|l|l|}
\hline Subjects & Management principles & Objects \\
\hline $\begin{array}{l}\text { Owners, managers, } \\
\text { employees, creditors, } \\
\text { consumers, suppliers, the } \\
\text { state. }\end{array}$ & $\begin{array}{l}\text { The combination of strategy and tactics, theory } \\
\text { and practice, accounting and planning; using an } \\
\text { institutional approach, the results of factor and }\end{array}$ & $\begin{array}{l}\text { Institutional environment, finance, } \\
\text { production, organizational structure, } \\
\text { scenario analysis; } \\
\text { optimization of management decisions. }\end{array}$ \\
$\begin{array}{l}\text { company, employees. } \\
\text { come image of the }\end{array}$ \\
\hline
\end{tabular}

The structure of company cost management system is shown in Fig.1. It reflects the main principle: the business is formed by the investor with the aim of obtaining maximum return on investment. Formulation and implementation of strategic goals of the business operation are presented in the corporate strategy. The investor (shareholder) invests capital both in the development of the objects, and in the development of the subjects (human capital), and in some cases provides the initial conditions for the impact of the subjects on the objects in the cost management system. The result is that the investor (shareholder), in case of successful business, increases the capital in the form of the business value increase.

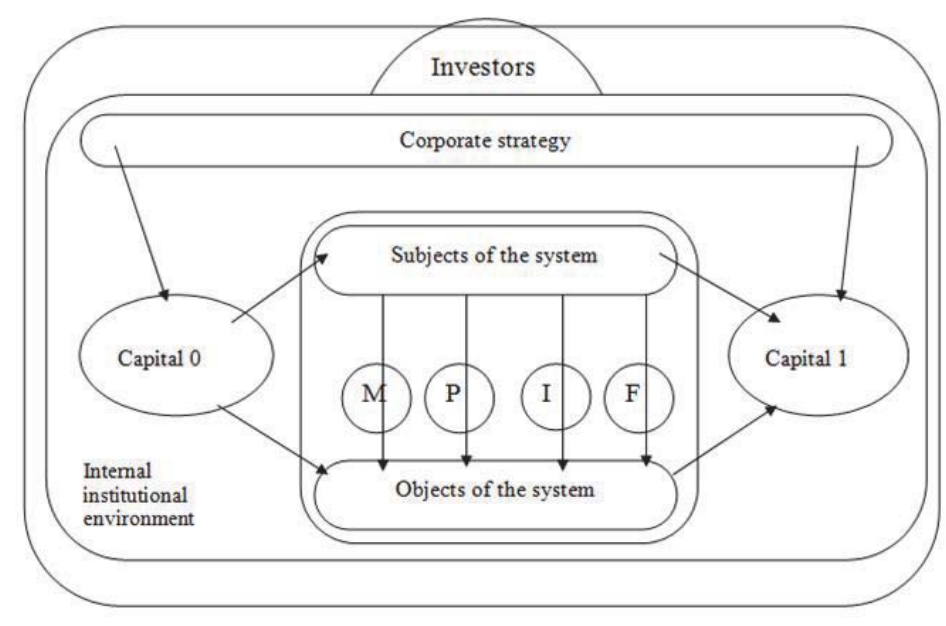

Fig. 1. System of company cost management (SCCM).

In the scheme in Fig.1, Capital 0 is the capital invested into the business. Capital 1 is the volume of capital available for the investor at the moment of the supposed coming out of business. The SCCM subjects are investors and managers of all levels, and the personnel. The SCCM objects is the property of the company and the intangible assets (intellectual capital). The subjects influence the objects in four functional spheres: in marketing (denoted as " $M$ " on the scheme), in production ("P"), in investment policy ("I"), and in finance ("F").

Despite the strict and consistent character of the proposed scheme of the company cost management system, its maintenance requires additions. The author (Т. Крамин, 2006) noted the fact that its central component is intellectual capital. For the model development in accordance with the modern post-industrial economy, one must specify the list of objects and subjects of cot management. In particular, the list of the system objects must include all the elements of intellectual capital, besides human capital: consumer, innovative, infrastructural, integrational, and institutional assets. When investing in the system subjects development, we should note, first of all, the formation of human capital.

The investor is influenced by external socio-economic environment, including the state. Management -level business functions in its information, or broader, institutional environment. The speed and effectiveness of the internal subjects of business (management) system depends on the speed and completeness of information flows in the system, which form the informational system of business, and the level of development of internal institutional environment.

As practice shows, the investment in human capital (Di Liberto, 2008) not only gives an effect mediated through the increase of financial assets, but also directly in the form of improving the company's image, prestige and reputation.

In our previous studies we have shown that the cost management should be based on the following four hierarchical levels (Т. Крамин, 2006; Т.В. Крамин \& Ю.С. Церцеил, 2008). 
The first level of managerial decision-making is the level of impact of a manager or a group of managers within a particular issue, problem.

The second level of competence fields is the level of acquired knowledge, developed skills and abilities of the company as a whole.

The third level of cost factors is the level of objectively existing conditions of value creation, grouped into functional groups within a single type or types of activities, or the national economy as a whole.

The fourth level of integrative value is the highest level of the system, where, on the basis of common definitions and measurement value criteria, the system efficiency and effectiveness are evaluated.

As it is, the specified levels of the system are arranged in a logical sequence. The making of managerial decisions is strategically determined by the choice of key competencies throughout the company. The selection of key competencies of the company, in turn, is determined on the basis of their potential impact on the cost factors on the market of the company products or services.

Furthermore, the managerial decisions should be considered as deals (transactions). Depending on the characteristics of the transaction, a particular contract is selected. Thus, the basis of cost management is transaction management and contractual relationships.

Thus, the basis of the model of valuation and cost management should be the system of managerial decisions, allowing to accurately determine the source of a particular change, and the degree of influence of each managerial decision, as well as its contribution to the creation of a new value.

In this case, managerial decision refers not only to the decision of a manager, but decisions of business owners in the framework of corporate management and of agency relationships management. Practice shows that the opportunistic behavior of investors has a high potential impact on the cost; a similar situation occurs at the level of company management.

After identifying the levels of a company value in CCMS, it is necessary to characterize the institutional environment in which they operate. The first three levels are in-house institutional environment. The most important internal institution is an organizational (corporate) culture, characterizing the effectiveness and promptness of the information system, the managerial decisions, the modelling systems, etc.

In addition, all CCMS levels function in the external institutional environment, including social, legal, and political institutions.

The above structure takes into account the specifics of the enterprise, associated with the enterprise intangible assets (intellectual capital). The level of managerial decision-making is a tactical level. However, in the process of intangible assets (IA) cost management, it is necessary to define the strategic orientation of the company in the field of their use. As is shown above, one can allocate a sufficiently large number of such assets. Effective management involves, however, not the management of all intangible assets, but the allocation of key intangible assets for the company, defining its uniqueness and, as a consequence, competitiveness. In this regard, we can highlight the key competence areas (KCA) of the company.

The most general definition of the KCA, which is used in the present study, was given by Harry Hamel (Hamel, 1996): "this is a set of skills, the possession of which is essential for the company to be able to compete successfully with other companies, as well as the foundation of its prosperity in the long term". "The set of skills", according to Hummel, can be attributed to the key competence area, if:

1) helps to increase the value of the company's products for the buyer who receives special benefits from the ownership of the products;

2) ensures the uniqueness of the company;

3) provides the ability of the company to enter new markets.

From the point of view of the set of intangible assets, the key competence area can be structured in the following way (Андриссен \& Тиссен, 2004):

1) valuable resources and acquisition (customer base, image and brand, supply chain, intellectual potential, embedded standards);

2) skills and tacit knowledge (know-how, knowledge and skills);

3) primary processes and management processes (management and control, information system);

4) technology and formalized knowledge (patents, manuals);

5) general moral values and norms (corporate culture, reliability, client-orientation).

To solve the above problems in the cluster functioning, Institute of Economics, Management and Law plans to form institutions the following competences in EI PPE and EI SPE:

1. Competences of strategic management: strategy formulation, operational refinement of strategy for a dynamic 
and highly competitive market of educational services.

2. Competencies of corporate management (the interaction of institutions).

3. Market competences: competence for the promotion of educational services in the market (marketing competence, the ability to quickly and accurately assess the needs of the population, organizations and society as a whole in the market of educational services).

4. Corporate culture forming competencies of "anchor" institution.

5. Infrastructure competences: the use of modern info-communication technologies, corporate system of business process of the branch network management.

6. Innovation competences: corporate culture development and innovation, the use of intellectual property objects of "anchor" institutions.

7. Competences in the field of financial management: project management technologies, cost savings and others.

8. Risk management competences.

Passing the intellectual capital accumulated by IEML to other educational institutions of the cluster, as well as other forms of partnershipsб will significantly increase the efficiency of EI PPE and EI SPE within the cluster, which is also consistent with the trends of higher education institutions development in the regional context (Birx, Anderson-Fletcher, \& Whitney, 2013; Chapman et al., 2011; Goddard \& Puukka, 2008).

Thus, the use of the hierarchical structure of the cost management system allowed to create and use a new classification of cluster interactions and the clusters themselves. The above model can be effectively used in the cost management of the scientific-educational cluster, as it comprehensively takes into account not only the economical but also institutional factors. The model pays special attention to the key competence areas of the organization, which play an important role in increasing the competitiveness of educational institutions in post-industrial economy.

\section{References}

Amaral, M., Ferreira, A., \& Teodoro, P. (2011). Building an entrepreneurial university in Brazil The role and potential of universityindustry linkages in promoting regional economic development. Industry and Higher Education, 25(5), 383-395.

Birx, D. L., Anderson-Fletcher, E., \& Whitney, E. (2013). Growing an Emerging Research University. Journal of Research Administration, 44(1), 11-35.

Chapman, D., Smith, H. L., Wood, P., Barnes, T., \& Romeo, S. (2011). University enterprise: the growth and impact of university-related companies in London. Industry and Higher Education, 25(6), 483-492.

Copeland, T. E., Koller, T., \& Murrin, J. (1994). Valuation: measuring and managing the value of companies.

Den Hertog, P., \& Remoe, S. (2001). Innovative clusters: drivers of national innovation systems: OECD Publishing.

Di Liberto, A. (2008). Education and Italian regional development. Economics of Education Review, 27(1), 94-107.

Gavrilov, A. V., \& Yaw, E. J. (2013). Formation of educational clusters, including Institutions of Different Level Professional Education. Paper presented at the Interactive Collaborative Learning (ICL), 2013 International Conference on.

Goddard, J., \& Puukka, J. (2008). The Engagement of Higher Educational Institutions in Regional Development: An Overview of the Opportunities and Challenges. Higher Education Management and Policy, 20(2), 3-33.

Gordon, I. R., \& McCann, P. (2000). Industrial clusters: complexes, agglomeration and/or social networks? Urban studies, 37(3), 513532.

Hamel, G. (1996). Competing for the Future: Harvard Business Press.

Korchagin, E. A., Safin, R. S., Vildanov, I. E., \& Abitov, R. N. (2014). Educational cluster as the element of Russian professional education system. Life Science Journal, 12(12s).

Safiullin, L. N., Fatkhiev, A. M., \& Grigorian, K. A. (2014). The Triple Helix Model of Innovation. Mediterranean Journal of Social Sciences, 5(18), 203.

Safiullina, A. M., Volkova, N. V., Petukhova, K. A., \& Guseva, L. A. (2014). The Formation and Development of the Managerial Personnel Reserve on the Example of the Tatarstan Republic. Mediterranean Journal of Social Sciences, 5(18), 33.

Nort, D. (1997). Institutyi, institutsionalnyie izmeneniya i funktsionirovanie ekonomiki. M.: Fond ekonomicheskoy knigi «Nachala, 74.

Varlamova J.A., Larionova N.I. Economic behavior of households: cross-country comparison. Life Science Journal 2014; 11(6s): 409413.

I.Sh. Khasanov, Three-sector structure of the national economy of Russia // Asian Social Science, Volume 10, 2014, Pages 217-224.

Vakhitova T.M., Gadelshina L.A. Directions of the region transport infrastructure development in the context of its competitiveness // Mediterranean Journal of Social Sciences vol. 5 № 24, November 2014, pp. 313-316. 